\title{
Experimental Study on Ice Slurry Refrigeration System with Pre-Cooling Heat Exchanger
}

\author{
Xukai Yang, Shengchun Liu* \\ Tianjin Key Laboratory of Refrigeration Technology, Tianjin University of Commerce, Tianjin, China \\ Email: ${ }^{*}$ liushch@tjcu.edu.cn
}

Received 26 March 2015; accepted 12 May 2015; published 13 May 2015

Copyright (C) 2015 by authors and Scientific Research Publishing Inc.

This work is licensed under the Creative Commons Attribution International License (CC BY).

http://creativecommons.org/licenses/by/4.0/

(c) (i) Open Access

\begin{abstract}
In the present study, the ice slurry refrigeration system with pre-cooling heat exchanger (ISSH) is studied experimentally to achieve the system performance, ice crystal formation time and the temperature of ice crystal formation. The operating parameters considered in this paper include the concentration of salt solution, suction pressure, discharge pressure and Energy Efficiency Ratio (EER). The result shows that the temperature of critical time of ice crystal formation decreases with the increasing concentration of salt solution and that the ice crystal formation time increases with the increasing concentration of salt solution. In the same concentration of salt solution, the ice crystal formation temperature of ISSH is lower than that of basic ice slurry refrigeration system (BISS), and the ice crystal formation time of ISSH is shorter than that of BISS. On the whole, the EER of ice slurry refrigeration system with pre-cooling heat exchanger is higher than that of basic ice slurry refrigeration system.
\end{abstract}

\section{Keywords}

Ice Slurry, Refrigeration System, Pre-Cooling, Heat Exchanger, EER

\section{Introduction}

In the history of fishery, ice as a cooling medium has been used for more than 100 years. The latent heat of melting of ice is about $335 \mathrm{~kJ} / \mathrm{kg}$, and the high enthalpy means that $1 \mathrm{~kg}$ ice can make about $10 \mathrm{~kg}$ fish's temperature reduce about $10^{\circ} \mathrm{C}$. Using the ice to preserve fish has many advantages that the ice water can clean the mucus and bacteria in the fish surface and can keep the fish isolated from the air to prevent the surface oxidation

"Corresponding author. 
and dry. The development of modern civilization further promotes the development of preservation technology, and the dynamic ice slurry is a new technology rapidly developed of fish freshness in recent years [1] [2].

With the development of mechanical refrigeration, ice slurry could be produced in different methods, such as the fluidized bed method, the vacuum method, the super-cooling method, the direct contact method and the scrape method [3]. High precision control of the surface temperature and the solid particle size are required for the fluidized bed method [4]. A high level of airtightness and vacuumization is required for the vacuum method [5] [6]. Satoh et al. [7] carried out an experiment for the cooling/freezing phenomena of a water droplet due to evaporation in an evacuated chamber, and analyzed the supercooling phenomena before the ice crystal formation. The influences of the supercooling degree, the refrigerant temperature and the flow rate on the crystallization have been studied by Bédécarrats et al. [8]. Due to the unstable super-cooling state, a low ice content and poor stability are found in the supercooling method [9]. For the direct contact method, the system where the refrigerant consumption is large is difficult to separate the refrigerant from the water, and the ice blockage in the nozzle often happens [10]. In the conventional ice slurry making system using the scraped surface type [11] [12], a circular shell-and-tube type heat exchanger is included, where the outer shell side is cooled by an evaporating refrigerant, and the inner side is scraped by spring loaded rotating blades to prevent any crystals from depositing on the cooled surface. However, some problems still exist in this system, for example the scrape part is easily damaged, and the system is complex and has a huge volume which is difficult to carry. This makes the fish cannot be cooled in time.

In this paper, ISSH is designed to experiment from system performance, ice crystal formation time and the temperature of ice crystal formation time. It aimed to provide some basis for the miniaturization of ice slurry refrigeration system.

\section{Experimental Installation}

To study the performance of the ISSH, an experimental ice slurry refrigeration system based on scraper type was first fabricated. The principle diagram of the experimental system is shown in Figure 1. The experimental system consists of a air-cooled condenser, a compressor, a salt solution pump, two throttles and an ice-making tank based on scraper type. Figure 2 presents the prototype of the dynamic ice slurry preparation unit, which includes a refrigeration circulation circuit and a coolant circulation circuit. The physical figure of ice slurry made up by experimental system is shown in Figure 3. In this study, R404A refrigerant is employed to cool the salt solution which the initial temperature is $16^{\circ} \mathrm{C}$ during the experiment process, and the evaporating temperature is $-10^{\circ} \mathrm{C}$ and the condensing temperature is $40^{\circ} \mathrm{C}$.

\section{Results and Discussion}

Thermocouples and pressure sensors was installed to gauge the temperature changes and pressure changes of the refrigerate and salt solution. By the data acquisition device, the influence of concentration of salt solution, suction pressure and discharge pressure on the system was obtained.

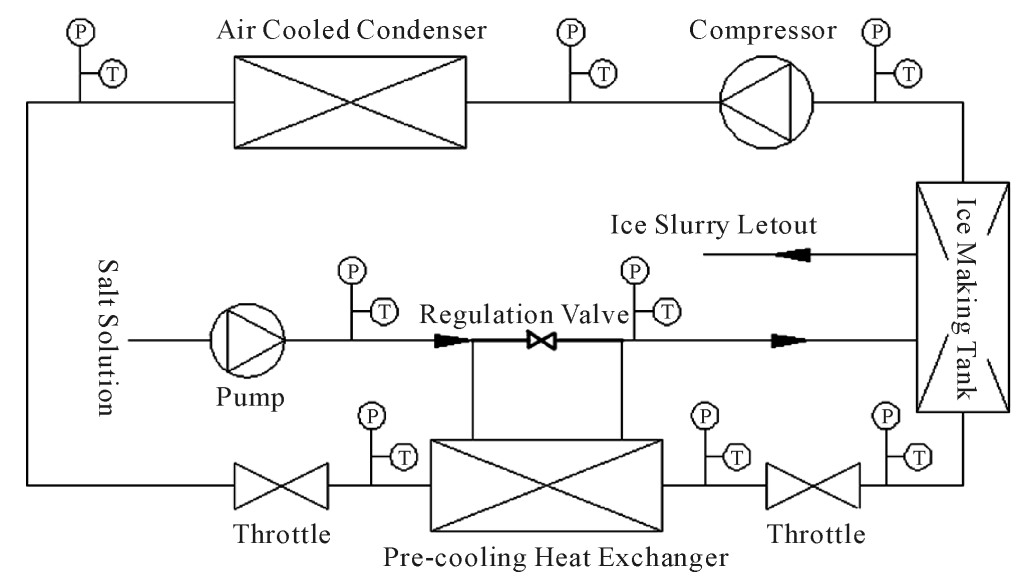

Figure 1. The principle diagram of the experimental system. 


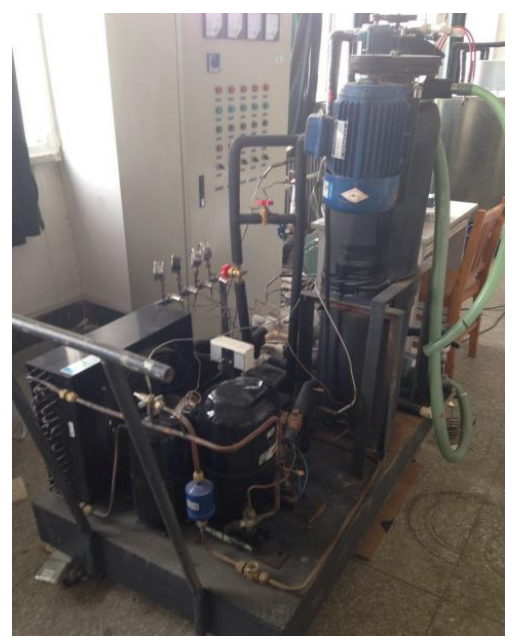

Figure 2. Prototype of the dynamic ice slurry preparation unit.

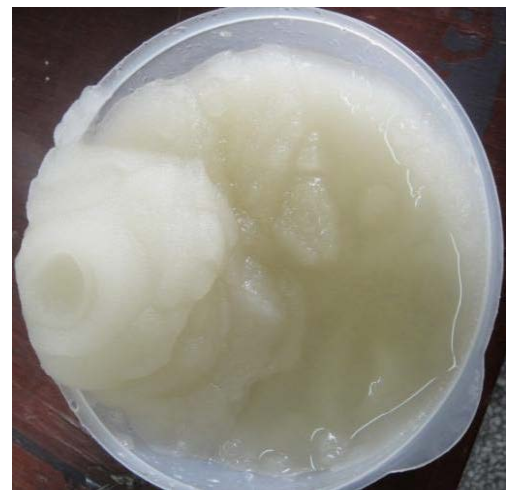

Figure 3. The physical figure of ice slurry made up by experimental methods.

The changing of temperature in the ice-making tank outlet with the time is shown in Figure 4. And Figure 5 shows one typical temperature changing in the ice-making tank outlet from BISS. From the chart it can be seen that a apparent temperature jump appears during the ice-making process. It is obvious that the salt solution temperature decreases very quick before the temperature jump appears, and after that the salt solution temperature continues to drop slightly. So the temperature change process can be divided into four stages: cooling section (AB), cold section (BC), ice crystal formation segment (CE) and stable segment (EF), and Tph is defined as the freezing point of salt solution. It is clearly that ice crystal formation process is promoted by the subcooling degree and the concentration of salt solution has a great effect on the subcooling degree. Thus, a fully understanding of the seawater's salt solution is very important to optimize the ISSH. From Figure 4, it is also evident that the temperature of the salt solution in the ISSH is much lower than that in BISS. Because of the sitting of the pre-cooling exchanger, the salt solution cooling rate is increased with the increases of the heat exchange area and the disturbance of salt solution in flow process.

According to the Raoult's law, it is well known that the vapor pressure of the salt solution is concerned with the salt concentration. With the increase of salt concentration, the vapor pressure of the salt solution declined, and resulting in a lower temperature of ice crystal formation. This can be seen in Figure 6 that the ice crystal formation temperature is decreased with the increasing of the salt solution. It also can be seen that the ice-making tank outlet temperature of the ISSH is lower than that of BISS. This phenomenon indicated that the position of ice crystal formation of the ISSH is anterior than that of BISS. This means that the ice-making tank can been designed smaller and the time of ice crystal formation will be shortened which can be seen in Figure 7. 


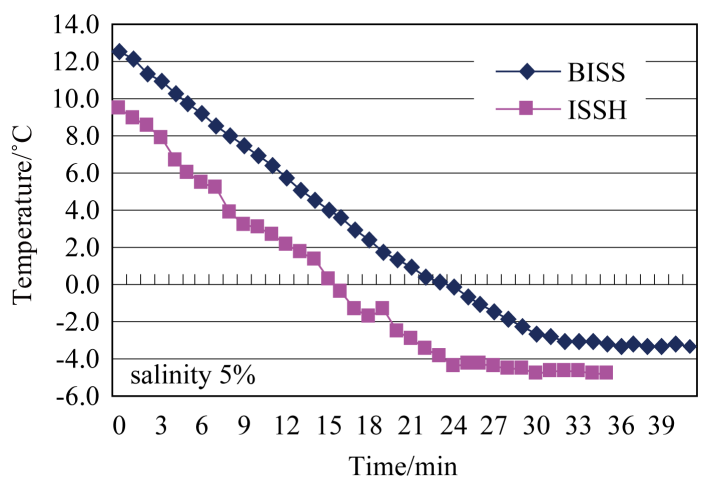

Figure 4. The changing of temperature in the icemaking tank outlet with the time.

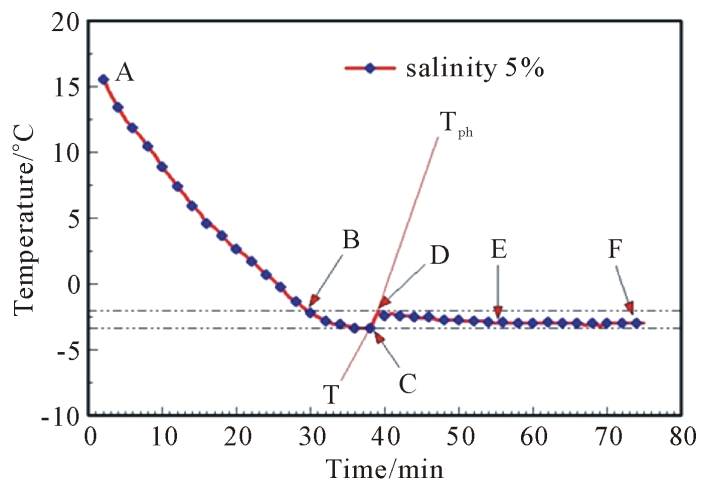

Figure 5. The typical temperature changing in the ice-making tank outlet from BISS.

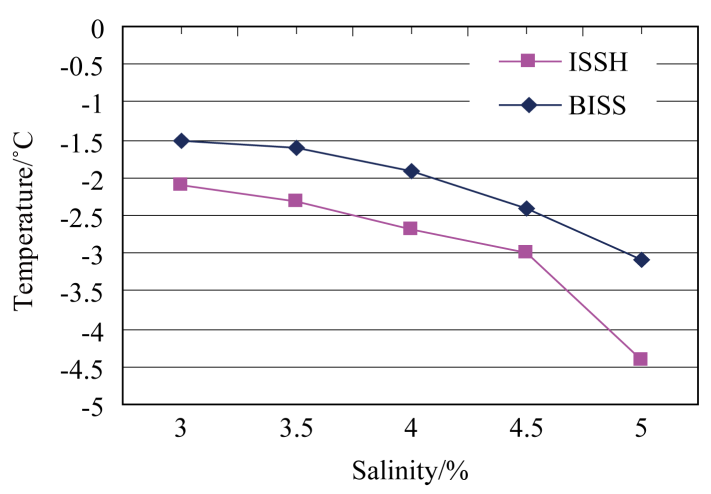

Figure 6. The temperature changing of ice crystal formation time with the salinity.

In Figure 7, the time of ice crystal formation of the ISSH is shorter than that of the BISS. From Figure 7, it is obvious that with the increases of salt solution, the ice crystal formation time is growing of the BISS, but the ice crystal formation time of ISSH is kept in almost 24 minutes. This means that the ISSH has a wide salt solution range and the ice crystal formation time is improved.

The pressure variation in the compressor suction and exhaust with time is shown in Figure 8 between the ISSH and the BISS. By analyzing Figure 8, we can see: the pressure variation trend in the compressor suction and exhaust in two systems is consistent, at the beginning of the experiment, pressure decreases greatly, at the beginning of the nucleus forming in salt solution, pressure appear different step degrees, then this fluctuation becomes gentle. This is because the temperature difference between refrigerant and salt solution decreases, and 


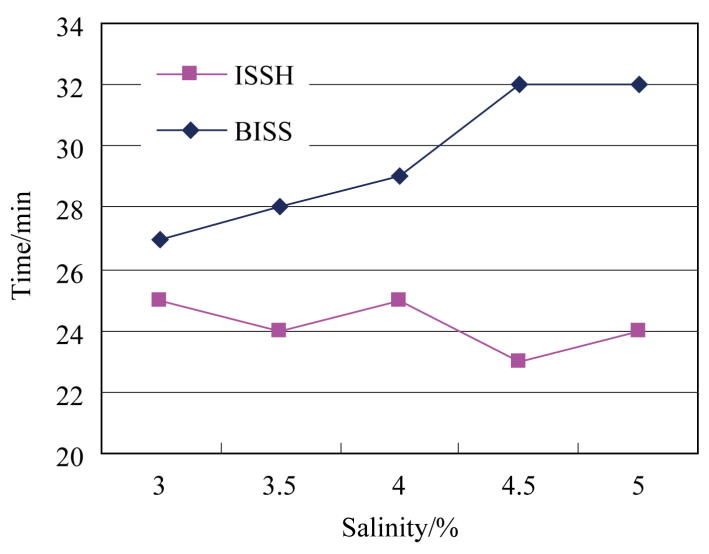

Figure 7. Ice crystal formation time changing with the salinity.
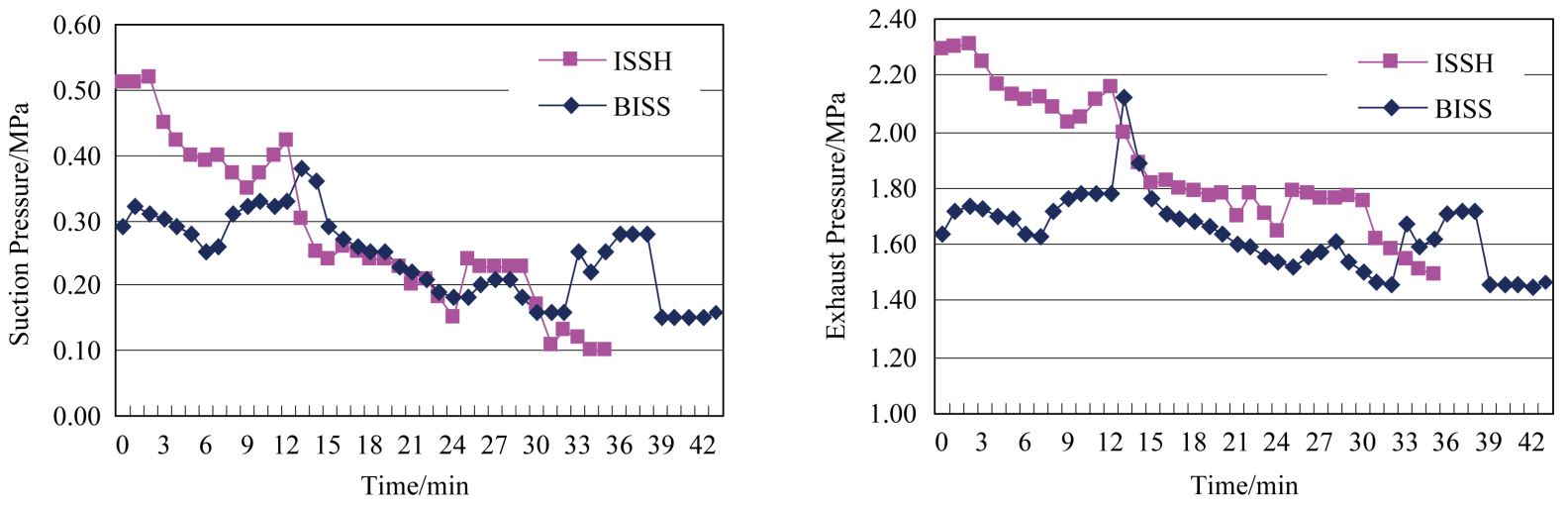

Figure 8. The compressor suction and exhaust pressure changing with the time.

leading to the fall in heat and the decreasing in superheating temperature of refrigerant. And we can also see from the figure, in the ISSH, pressure changes greatly, this is because pre-cooling exchanger enhances the disturbance of refrigerants, increases the flow resistance, so the pressure drop in pipeline is greater than that of BISS. And the pressure step is caused by the overheating in refrigerant in the process of crystal nucleus growth stage in salt solution.

From the figure, the pressure variation trend in the compressor suction and exhaust in two systems is consistent, compressor ratio fluctuates little according to time, which shows in the process of system running, compressor has mall variations in power consumption and good stability.

The EER of refrigerating system changing with the time between the ISSH and the BISS is shown in Figure 9 and Figure 10, it is not hard to see, without pre-cooling exchanger, the maximum EER is 1.71 in the BISS, and the salt concentration is $4 \%$; with the pre-cooling exchanger, the EER is 2.59 and the salt concentration is $4.5 \%$. Under the same salt concentration, the EER in ISSH is improved. The EER in BISS and ISSH is 0.7 and 1.0, increased by $43 \%$.

\section{Conclusions}

Research of dynamic ice slurry ice-making system experiment is carried out; system parameters in different salt concentrations and different system modes (ISSH and BISS) are analyzed. The experimental results show that:

1) With the raise of salt solution concentration during the experiment process, the ice crystal formation temperature trends to decrease and the ice crystal formation time trends to increase;

2) Under the same salt solution concentration, the outlet temperature of the salt solution in ice-making tank is significantly short after having pre-cooling exchanger by $25 \%$. On the premise of device miniaturization, precooling effect and the device size should be considered in the process of pre-cooling optimization; 


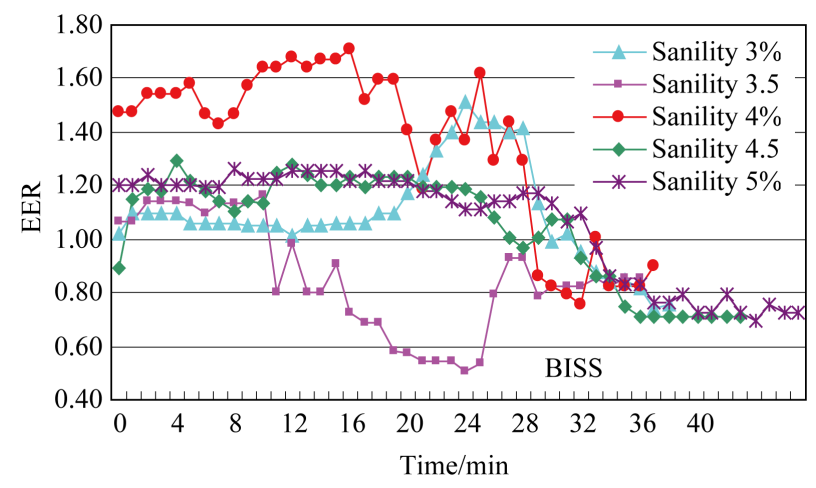

Figure 9. The EER of refrigerating system changing with the time of BISS.

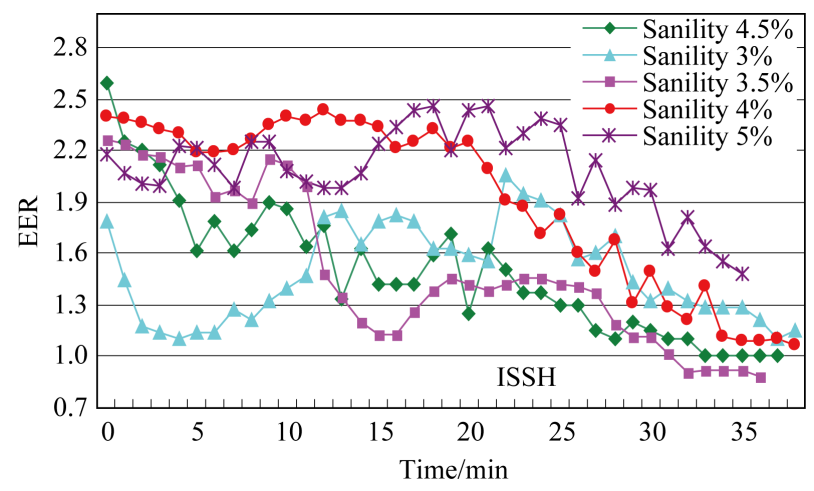

Figure 10. The EER of refrigerating system changing with the time of ISSH.

3) The maximum EER in BISS is 0.7 and in ISSH is 1.0 , increased by $43 \%$;

4) The seawater can be used in this system directly. In the future, the pre-cooling exchanger will be optimized with some strengthening heat transfer technologies, which makes the system smaller and convenient to use in fisher and market.

\section{Acknowledgements}

The work in this paper is supported by the science research innovation team project in Tianjin City, China"Energy saving of equipment in food cold chain and new technologies in refrigerated transportation" (TD125048).

\section{References}

[1] Liu, S.C., Wang, F.B. and Sun, Z.L. (2009) Slurry Ice Technology and Its Application in the Field of Food Preservation and Others. Proceeding of Chinese Association of Refrigeration, Tianjin, 2009.

[2] Wang, M.J. and Kusumoto, N. (2010) Ice Slurry Based Thermal Storage in Multifunctional Buildings. Heat and Mass Transfer, 37, 597-604. http://dx.doi.org/10.1007/PL00005891

[3] Kauffeld, M., Wang, M.J., Goldstein, V. and Kasza, K.E. (2010) Ice Slurry Applications. International Journal of Refrigeration, 8, 1491-1505. http://dx.doi.org/10.1016/j.ijrefrig.2010.07.018

[4] Meewisse, J.W. and Ferreira, C.A.I. (2003) Validation of the Use of Heat Transfer Models in Liquid/Solid Fluidized Beds for Ice Slurry Generation. International Journal of Heat and Mass Transfer, 19, 3683-3695. http://dx.doi.org/10.1016/S0017-9310(03)00171-6

[5] Meewisse, J.W. (2004) Fluidized Bed Ice Slurry Generator for Enhanced Secondary Cooling Systems. Ph.D. Thesis, Delft University of Technology, Delft.

[6] Kim, B.S., Shin, H.T., Lee, Y.P. and Jurng, J. (2001) Study on Ice Slurry Production by Water Spray. International 
Journal of Refrigeration, 24, 176-184. http://dx.doi.org/10.1016/S0140-7007(00)00013-X

[7] Satoh, I., Fushinobu, K. and Hashimoto, Y. (2002) Freezing of a Water Droplet Due to Evaporation-Heat Transfer Dominating the Evaporation-Freezing Phenomena and the Effect of Boiling on Freezing Characteristics. International Journal of Refrigeration, 25, 226-234. http://dx.doi.org/10.1016/S0140-7007(01)00083-4

[8] Bédécarrats, J.-P., David, T. and Castaing-Lasvignottes, J. (2010) Ice Slurry Production Using Supercooling Phenomenon. International Journal of Refrigeration, 33, 196-204. http://dx.doi.org/10.1016/j.ijrefrig.2009.08.012

[9] Tassou, S.A., Lewis, J.S., Ge, Y.T., Hadawey, A. and Chaer, I. (2010) A Review of Emerging Technologies for Food Refrigeration Applications. Applied Thermal Engineering, 4, 263-276. http://dx.doi.org/10.1016/j.applthermaleng.2009.09.001

[10] Thongwik, S., Vorayos, N., Kiatsiriroat, T. and Nuntaphan, A. (2008) Thermal Analysis of Slurry Ice Production System Using Direct Contact Heat Transfer of Carbon Dioxide and Water Mixture. International Communications in Heat and Mass Transfer, 35, 756-761. http://dx.doi.org/10.1016/j.icheatmasstransfer.2008.02.007

[11] Stamatiou, R., Meewisse, J.W. and Kawaji, M. (2005) Ice Slurry Generation Involving Moving Parts. International Journal of Refrigeration, 28, 60-72.

[12] Kim, B.S., Shin, H.T. and Lee, Y.P. (2001) Study on Ice Slurry Production by Water Spray. International Journal of Refrigeration, 24, 176-184. http://dx.doi.org/10.1016/S0140-7007(00)00013-X 